J. Lake Sci.(湖泊科学), 2009, 21(5): 725-731

http://www.jlakes.org. E-mail: jlakes@niglas.ac.cn

(C)2009 by Journal of Lake Sciences

\title{
江苏省生态保护与建设空间分布耦合状态评价*
}

\author{
陈 诚 ${ }^{1,2}$, 陈 雯 $^{1}$, 吕卫国 ${ }^{1,2}$ \\ (1: 中国科学院南京地理与湖泊研究所, 南京 210008) \\ (2: 中国科学院研究生院, 北京 100049)
}

摘 要: 根据生态空间保护需求, 调整产业与城镇开发方向, 是协调建设布局与生态保护空间关系, 进行区域空间引导和控 制的重要内容. 以江苏省为案例区，在划定生态功能保护区、提取现状建设空间分布信息的基础上，运用矩阵分类和空间分析 方法研究了生态功能保护区与建设空间的耦合特征及生态功能保护区的建设占用状况，总结了空间开发秩序调整思路. 研究 表明: 江苏大部分地区生态保护与建设空间耦合基本协调, 不协调的区域主要分布于无锡、常州等地区, 未来需控制该区建设 空间的增长; 重要湿地、水源涵养区和风景胜区等生态保护区的建设占用规模较大, 未来空间开发应予以避让; 农居空间占用 生态功能保护区的面积较大, 未来可通过合理调整农居空间的布局逐步减少对生态功能保护区的占用, 降低生态系统压力, 促进生态服务功能维护.

关键词: 生态功能保护区; 建设空间; 空间耦合; 江苏省

\section{Assessment of spatial coupling between construction space and ecological protection areas in Jiangsu Province}

\author{
CHEN Cheng ${ }^{1,2}$, CHEN Wen ${ }^{1}$, Lü Weiguo ${ }^{1,2}$ \\ (1: Nanjing Institute of Geograhpy and Limnology, Chinese Academy of Sciences, Nanjing 210008, P.R.China) \\ (2: Graduate University of Chinese Academy of Sciences, Beijing 100049, P.R.China)
}

Abstract: It is an important part of harmonizing the spatial relationship between development and ecological protection and development leading and space control to adjust the spatial arrangement of industry and town according to the distribution of ecological protection space. Taking Jiangsu Province as a case, matrix-analysis and spatial analysis method was applied to exploring the spatial coupling characteristic of ecological function protection area and construction land and status of the ecological function area occupied by space development based on extracting the information of ecological functional protection zones and construction land distribution, later the adjusting route of space order was recommended. Conclusions were as follows: Firstly, the spatial coupling relationship between ecological function protection area and construction land was harmonious in most part of Jiangsu Province, but Suzhou and Wuxi cities were out of line, the construction land's expanding should be decreased in the future. Secondly, construction land occupies a large part of important everglade, riverhead protection area, and landscape area, spatial development should keep away from them. Thirdly, the ecological function area covered by the rural resident area is larger than other kind construction land, so the pressure on the region's ecosystem can be alleviated by the way of changing the spatial distribution of rural resident area in the further.

Keywords: Ecological functional protection zones; construction land space; space coupling; Jiangsu Province

随着工业化和城市化进程的不断加速，建设空间不断曼延，占用自然生态空间的步伐加快，生态系 统胁迫过程不断加强，区域生态安全受到到威胁，已经成为区域社会经济持续发展的障碍 ${ }^{[1]}$. 控制建设空

* 国家自然科学基金项目(40771053)和中国科学院知识创新工程项目(KZCY2-YW-339)联合资助. 2008-12-08 收稿; 2009-03-19 收修改稿. 陈诚, 男, 1983 年生, 博士研究生; E-mail: chchen@niglas.ac.cn. 
间的无序蔓延并引导其在合理区域增长是协调区域生态保护与建设空间矛盾、规范空间开发秩序的重要 途径. 相关研究对此做了较多探讨: 城市精明增长理念强调从区域层面划定各类具有重要自然资源保护 价值和生态敏感区域作为城市增长边界以控制城市的无序蔓延，引导城市发展的速率和方向，以此调节 城市建设与生态保护的空间矛盾 ${ }^{[2-5]}$, 从测度人类社会经济发展对各类生态空间需求与生态环境承载力 之间的关系角度进行区域生态安全、生态压力评价方面的研究也有一定的基础 ${ }^{[6-8]}$, 至于生态保护与建设 空间之间的关系研究还相对比较薄弱, 本研究试图通过提取生态功能保护区和建设空间分布信息, 权衡 生态保护重要性和建设空间供给保障的空间差异, 评价案例区生态保护与建设用地空间分布的耦合特征 和生态保护空间的建设占用特点，探寻空间开发引导、协调生态保护与空间开发布局关系的思路与方法, 以期为区域可持续发展提供指导.

江苏位于我国沿海地区中部, 地跨长江、淮河两大流域, 介于东经 $116^{\circ} 18^{\prime}-121^{\circ} 57^{\prime}$, 北纬 $30^{\circ} 45^{\prime}-$ $35^{\circ} 20^{\prime}$ 之间. 全省地势低平, 河湖众多, 低山丘陵仅占 $14 \%$, 且集中在省域西南和北部. 淮河-灌溉总渠一 线以南属亚热带湿润季风气候, 以北属暖温带湿润季风气候, 四季分明, 水热同期. 2007年末全省人口密 度715人/平方公里, 是全国人口密度的五倍; 人均GDP33689元, 位于全国前列. 由于人口和经济规模较 大, 部分地区建设空间过度扩张、生态空间的建设占用较多, 生态系统压力巨大, 生态系统服务功能退化. 因此, 以江苏省为案例区具有一定的典型意义.

\section{1 数据来源与研究方法}

\section{1 数据来源}

江苏全省1:50000基础地理数据、Spot4和Landsat-5融合后空间分辨率达 $10 \mathrm{~m}$ 遥感影像、空间分辨率约 为 $90 \mathrm{~m}$ DEM 、《江苏省“十一五”环境保护和生态建设规划》.

\section{2 研究方法}

1.2.1 生态保护空间与建设空间分布信息提取 (1)生态功能保护区划定. 生态功能保护区的划定以生态系 统服务功能空间分异、区域空间相关为基本原则, 旨在识别具有水源涵养、水土保持、生物多样性维护、 自然与人文景观保护、防风固沙等重要生态服务价值的区域 ${ }^{[9]}$, 并依据生态系统类型、特征及主导生态 服务功能差异进行分类. 本研究结合已建的各类特别保护区将江苏省生态功能保护区分为自然保护区、 风景名胜区、森林公园、地质遗迹、水源涵养区、饮用水源保护区、清水通道维护区、重要湿地、重要 渔业水域、行蓄滞洪区、生态公益林区等11个类型.

边界确定是生态功能保护区划定的关键，研究以保持生态系统结构完整性、主导生态服务功能一致 性以及行政区划完整性为准则 ${ }^{[9]}$, 依据地形、水系、植被等自然生态条件的空间分布特征, 确定各类生态 功能保护区边界; 其中政府批复已建的各类保护区如：自然保护区、风景名胜区、森林公园、地质公园 等的边界以批复范围为准, 具体边界描述见表 1.

(2)建设空间分布信息获取. 基于Erdas 9.0软件平台，对原始影像进行几何纠正、正射校正、影像融合 和图像增强等预处理之后, 通过光谱特征、纹理特征分析与实地调查相结合的方式建立解译标志, 以目 视判读的方式提取建设空间信息，并进行精度校正. 结合新版《土地利用现状分类》(2007)将建设空间分 为城市建成区、城镇建成区、农村居民点、独立工矿、盐田、高速公路、一般公路、铁路、机场和其它 建设用地等10类, 图斑取舍参照《1:50000地形图编绘规范(GB/T12343-1990)》进行.

1.2.2 生态保护空间与建设空间分布耦合模式识别与评价 (1)生态保护空间与建设空间分布耦合模式识 别. 计算各地市生态功能保护区和建设空间的面积比例, 运用聚类分析方法进行生态功能保护空间和建 设空间面积比重的等级划分, 分别以生态保护空间和建设空间比重等级为行和列建立矩阵, 根据生态保 护空间和建设空间比重等级的组合类型 ${ }^{[10-11]}$, 按照优先保护生态、控制空间开发的准则, 结合专家经验 进行江苏省域生态保护空间和建设空间分布耦合类型划分.

(2)不同耦合类型区域生态保护空间建设占用特征分析. 基于ArcGIS平台, 叠置(intersect)生态功能保 护区、建设空间和地市边界三层空间数据, 利用交叉统计方法分析各耦合类型区域生态功能保护区的建 设占用及其空间分布特征，并从维护区域生态服务功能保护区的主导功能出发，评价现状建设空间分布 
的合理性，总结未来建设空间开发秩序调整的思路.

表1 生态功能保护区类别及范围分布

Tab.1 Classification and range of ecological function protection areas

\begin{tabular}{|c|c|c|}
\hline 类别 & 主导生态服务功能 & 范围 \\
\hline 自然保护区 & 生物多样性保护 & 政府批复的自然保护区范围, 包括核心区、 \\
\hline & $\begin{array}{l}\text { 自然与人文景观 } \\
\text { 保护 }\end{array}$ & $\begin{array}{l}\text { 自然与人文景观集中、环境优美可供人们游览或进行科学文化活动的 } \\
\text { 区域 }\end{array}$ \\
\hline 森林公园 & $\begin{array}{l}\text { 自然与人文景观 } \\
\text { 保护 }\end{array}$ & $\begin{array}{l}\text { 自然与人文景观集中、森林景观优美可供人们游览或进行科学文化活 } \\
\text { 动的区域 }\end{array}$ \\
\hline 水源涵养区 & & $\begin{array}{l}\mathrm{n} \text { 以上、植被覆盖良好的丘陵山地, 其它河流源头汇水区以及 } \\
\text { 库的径流汇聚区 }\end{array}$ \\
\hline 饮用水源 & 水源水质保护 & $\begin{array}{l}\text { 库、湖泊取水口周围一二级与准保护区和小型水库水体 } \\
\text { 域 }\end{array}$ \\
\hline $\begin{array}{l}\text { 清水通道 } \\
\text { 维护区 }\end{array}$ & 水源水质保护 & $\begin{array}{l}\text { 的水体及两侧100m陆域部分(非城区段)、城区段水涯线至两 } \\
\text { 心线 }\end{array}$ \\
\hline 行蓄滞洪区 & 洪水调蓄 & 的河道、湖泊沿岸主堤防之间的水域和滩地 \\
\hline 重要渔业水域 & 渔业繁殖保护 & $\begin{array}{l}\text { 河流、湖泊与海洋珍稀鱼类种质资源繁殖与保护及其它渔业资源集中 } \\
\text { 分布的水域 }\end{array}$ \\
\hline 重要湿地 & 湿地生 & (太湖、洪泽湖等省管大型湖泊)湿地、江河(长江、废黄河) \\
\hline & & \\
\hline 地质遗迹 & $\begin{array}{l}\text { 地质遗 } \\
\text { 景观保 }\end{array}$ & $\begin{array}{l}\text { 具有特殊研究与保护价值的地质构造、剖面、古生物化石、宝玉石及 } \\
\text { 其典型产地 }\end{array}$ \\
\hline 生态公益林区 & 涵养水源 & 能提供公益性、社会性产品或服务的其它森林、林木和林地地区 \\
\hline
\end{tabular}

\section{2 结果分析}

\section{1 生态保护与建设空间特征分析}

2.1 .1 生态保护空间分布 全省生态功能保护 区总面积为 $12727.65 \mathrm{~km}^{2}$ (不含大型水面), 其 中自然保护区面积最大, 为 $4160.74 \mathrm{~km}^{2}$, 占 比达32.69\%，主要分布于苏北滨海地区和洪 泽湖、骆马湖等大型湖泊沿岸地区; 重要湿地 面积次之, 为 $2824.49 \mathrm{~km}^{2}$, 占比为 $22.19 \%$, 集 中于湖泊、河流沿岸及苏中里下河洼地和太湖 水网平原地区; 水源涵养区面积为 $1845.48 \mathrm{~km}^{2}$, 占比 $14.50 \%$, 主要分布在省域北部和西南低 山丘陵地区; 其它生态功能保护区面积相对 较小, 清水通道维护区主要分布在南水北调 东线、通榆运河等跨区域调水通道沿线地区, 风景名胜区、森林公园和生态公益林区等的 分布则较为零散, 饮用水源保护区则分布在 主要的取水口周边地区(图1).

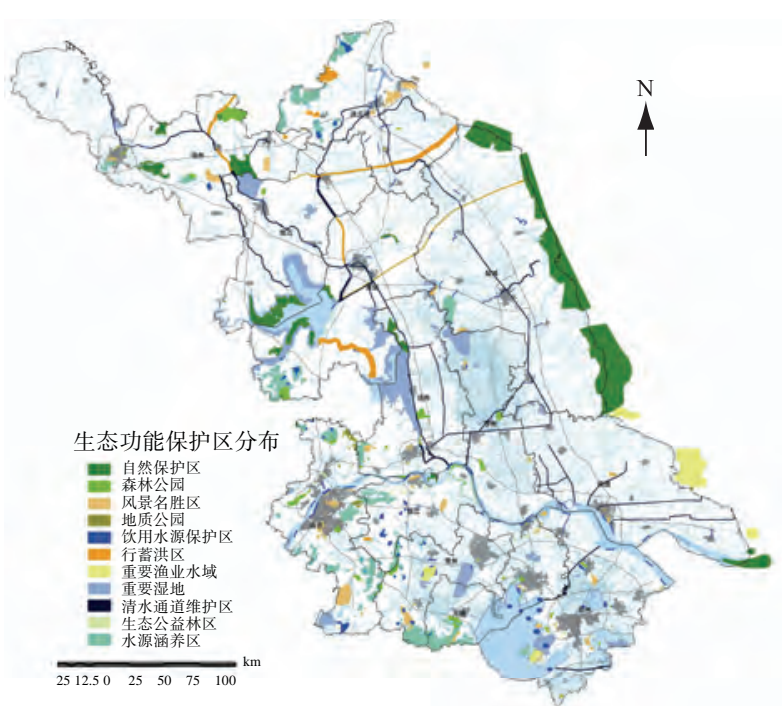

图 1 江苏省生态功能保护区分布示意图

Fig.1 The distribution of different kinds of ecological function protection area 
2.1.2 建设空间分布 为分析统计方便, 将城市建成区与城镇建成区合并为城镇空间, 铁路、一般公路、 高速公路、机场用地合并为交通空间. 2007年全省建设空间总面积为 $15304.22 \mathrm{~km}^{2}$ (不含盐田), 其中城镇和 农居空间面积较大，占比分别为 $34.77 \%$ 和 $43.80 \%$. 地市建设空间比重分布方面, 苏州、常州、无锡等苏南 地市建设空间比重较高, 分别为 $29.77 \% 、 25.25 \%$ 和 $24.27 \%$; 盐城市和淮安市等苏北地市相对较低, 仅为 8.73\%和 $9.30 \%$; 其它地市位于 $14 \%$ 至 $18 \%$ 之间. 各类建设空间的分布方面, 城镇、工矿及其它建设空间主 要分布于苏南及沿江的苏、锡、常、宁、通等地市, 如苏州、无锡、南京三市城镇空间面积分别占全省 的 $18.59 \%$ 、 $14.69 \%$ 和 $10.66 \%$, 苏州、常州和南通三市独立工矿空间面积分别占全省 $24.75 \%$ 、15.78\%和 $13.8 \%$ ，苏州、南京和无锡三市的其它建设空间分别占全省 $35.18 \%$ 、29.93\%和 $15.60 \%$; 农居空间和交通空 间则集中于苏北地市，如徐州、盐城、南通和宿迁等市的农居空间分别占全省的 $14.33 \% 、 13.12 \% 、 11.13 \%$ 和 $10.97 \%$, 徐州和盐城两地市交通空间分别占全省的 $21.11 \%$ 和 $10.35 \%$, 与地域面积有较大联系(表2).

表2 建设空间面积统计(\%)

Tab.2 Area statistic of different kinds of construction space

\begin{tabular}{ccccccc}
\hline 地市 & $\begin{array}{c}\text { 建设空间占国 } \\
\text { 土面积比例 }\end{array}$ & $\begin{array}{c}\text { 城镇空间占 } \\
\text { 全省比例 }\end{array}$ & $\begin{array}{c}\text { 农居空间 } \\
\text { 占全省比例 }\end{array}$ & $\begin{array}{c}\text { 独立工全省比例 } \\
\text { 占全省比例 }\end{array}$ & $\begin{array}{c}\text { 交它建设空间 } \\
\text { 占全省比例 }\end{array}$ \\
\hline 南京市 & 17.59 & 14.69 & 2.00 & 7.68 & 4.58 & 29.93 \\
无锡市 & 24.27 & 10.66 & 4.29 & 7.03 & 2.81 & 15.60 \\
徐州市 & 16.83 & 6.86 & 14.33 & 3.68 & 21.11 & 0.00 \\
常州市 & 25.25 & 7.93 & 5.28 & 15.78 & 5.07 & 0.00 \\
苏州市 & 29.77 & 18.59 & 6.93 & 24.75 & 6.35 & 35.18 \\
南通市 & 14.17 & 6.82 & 11.13 & 13.08 & 8.15 & 0.00 \\
连云港市 & 13.53 & 4.26 & 7.99 & 2.26 & 9.81 & 4.56 \\
淮安市 & 9.30 & 4.89 & 6.42 & 2.73 & 6.00 & 0.00 \\
盐城市 & 8.73 & 6.79 & 13.12 & 2.16 & 10.35 & 9.59 \\
扬州市 & 15.95 & 6.47 & 5.67 & 6.52 & 8.28 & 0.00 \\
镇江市 & 15.19 & 3.42 & 3.34 & 7.39 & 3.59 & 3.29 \\
泰州市 & 17.07 & 4.35 & 8.52 & 4.28 & 5.08 & 1.85 \\
宿迁市 & 15.01 & 4.27 & 10.97 & 2.65 & 8.82 & 0.00 \\
总计 & 15.46 & 100.00 & 100.00 & 100.00 & 100.00 & 100.00 \\
\hline
\end{tabular}

\section{2 生态保护与建设空间耦合类型及生态保护空间建设占用分析}

2.2.1 生态保护与建设空间耦合类型通过矩阵分析, 将各地市划分不协调、较不协调和基本协调三种耦 合类型区域(图2).

不协调区域: 指生态保护空间比重高、且建设空间比重高的地区, 生态保护需求强烈, 但现状开发强 度较大, 需要降低地区开发强度增速, 减轻生态系统压力. 该区域包括太湖上游的常州与无锡两市, 面 积相对较小, 为 $9172.18 \mathrm{~km}^{2}$, 约占全省 $8.70 \%$; 其重要生态功能保护区和建设空间面积为 $1356.90 \mathrm{~km}^{2}$ 和 $2025.50 \mathrm{~km}^{2}$, 各全省的 $10.66 \%$ 和 $13.23 \%$.

较不协调区域: 指生态保护空间比重较高、建设空间比重中等及偏高的地区, 生态保护的需求较强, 现状开发强度相对较高, 需要控制区域开发强度增速. 该类区域包括南京和苏州以及洪泽湖北部的宿迁 等市, 面积相对较大, 约占全省 $22.40 \%$; 其重要生态功能保护区和建设空间分别占全省的 $22.33 \%$ 和 $26.99 \%$.

基本协调区域: 指生态保护空间比重较高、建设空间比重较低或生态保护空间比重较低、建设空间 比重中等和偏低的地区, 前者生态保护需求较强、需保持较低的建设空间比例, 主要包括苏北的淮安、 盐城和连云港等市; 后者生态保护需求较弱、可以承担较高强度的开发, 促进人口、经济集聚, 主要包括 
沿江和沿海的镇江、扬州、泰州和南通等市. 该类区域面积最大, 约占全省 $68.91 \%$; 其重要生态功能保护 区和建设空间各全省的 $67.01 \%$ 和 $59.78 \%$ (表4).

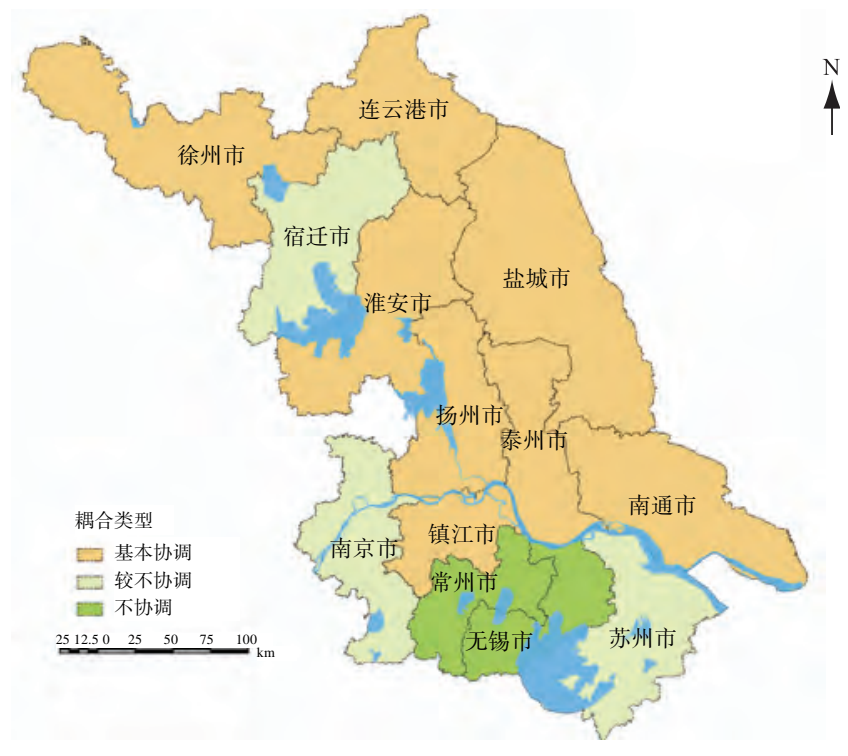

图 2 生态保护与建设空间耦合类型分布

Fig.2 The spatial distribution of ecological protection and construction space coupling type

表3 三类区域面积统计

Tab.3 Area statistic of different coupling type regions

\begin{tabular}{ccccccc}
\hline 区域类型 & $\begin{array}{c}\text { 国土面积 } \\
\left(\mathrm{km}^{2}\right)\end{array}$ & $\begin{array}{c}\text { 占全省比重 } \\
(\%)\end{array}$ & $\begin{array}{c}\text { 生态功能 } \\
\text { 保护区面积 }\left(\mathrm{km}^{2}\right)\end{array}$ & $\begin{array}{c}\text { 占全省比重 } \\
(\%)\end{array}$ & $\begin{array}{c}\text { 建设空间 } \\
\text { 面积 }\left(\mathrm{km}^{2}\right)\end{array}$ & $\begin{array}{c}\text { 占全省比重 } \\
(\%)\end{array}$ \\
\hline 不协调区域 & 9172.18 & 8.70 & 1356.90 & 10.66 & 2025.50 & 13.23 \\
较不协调区域 & 23623.84 & 22.40 & 2842.14 & 22.33 & 4130.00 & 26.99 \\
基本协调区域 & 72687.52 & 68.91 & 8528.61 & 67.01 & 9148.71 & 59.78 \\
总计 & 105483.54 & 100.00 & 12727.65 & 100.00 & 15304.22 & 100.00 \\
\hline
\end{tabular}

2.2.2 不同耦合类型区域生态功能保护空间建设占用特征各类生态功能保护区的建设占用比例差异分 析. 整体上, 不协调区域生态功能保护区的建设占用比例最高、较不协调区域次之、基本协调区域最低, 分别为 $5.63 \% 、 5.07 \%$ 和 $4.00 \%$, 呈逐步下降趋势(表4). 在不同耦合类型区域中, 各类生态功能保护区的建 设空间占用特征差异显著. (1)不协调区域中, 地质遗迹保护区的建设占用比例最高, 达 $74.36 \%$, 生态公 益林区和重要湿地的建设占用比例次之, 分别为 $16.86 \%$ 和 $15.17 \%$, 其它类型生态功能保护区的建设占用 比例相对较低; 重要湿地和水源涵养区的建设占用面积较大, 分别占该区域生态保护空间建设占用总量的 43.44\%和30.38\%, 其它生态功能保护区的建设占用面积较小. (2)在较不协调区域中, 生态公益林区和风景 名胜区的建设占用比例较高, 分别为 $13.44 \%$ 和 $12.15 \%$, 其它类型生态功能保护区建设占用比例相对较低. 重要湿地、风景名胜区和水源涵养区的建设占用面积较大, 分别占该类区域生态保护空间建设占用总量 的44.68\%、17.99\%和10.32\%, 其它生态功能保护区的建设占用面积较小. (3)在基本协调区域中, 清水通道 维护区、风景名胜区和森林公园的建设占用比例较高, 分别为 $11.15 \% 、 11.35 \%$ 和 $11.69 \%$, 其它类型生态 功能保护区建设占用比例相对较低. 清水通道维护区、风景名胜区、重要湿地、水源涵养区和森林公园 的建设占用面积较大且差别较小, 比例位于 $12 \%-20 \%$ 之间, 其它生态功能保护区的建设占用面积较小. 
表4 各耦合类型区生态保护空间建设占用面积与比例统计

Tab.4 Statistics of Area and ratio of ecological protection space covered by construction land in different regions

\begin{tabular}{|c|c|c|c|c|c|c|c|c|c|}
\hline \multirow[b]{2}{*}{$\begin{array}{c}\text { 生态功能区 } \\
\text { 类型 }\end{array}$} & \multicolumn{3}{|c|}{ 不协调区域 } & \multicolumn{3}{|c|}{ 较不协调区域 } & \multicolumn{3}{|c|}{ 基本协调区域 } \\
\hline & $\begin{array}{l}\text { 被占面 } \\
\text { 积 }\left(\mathrm{km}^{2}\right)\end{array}$ & $\begin{array}{l}\text { 被占比 } \\
\text { 例(\%) }\end{array}$ & $\begin{array}{c}\text { 占被占总 } \\
\text { 面积比例 } \\
(\%)\end{array}$ & $\begin{array}{l}\text { 被占面 } \\
\text { 积 }\left(\mathrm{km}^{2}\right)\end{array}$ & $\begin{array}{l}\text { 被占比 } \\
\text { 例(\%) }\end{array}$ & $\begin{array}{c}\text { 占被占总 } \\
\text { 面积比例 } \\
(\%)\end{array}$ & $\begin{array}{l}\text { 被占面 } \\
\text { 积 }\left(\mathrm{km}^{2}\right)\end{array}$ & $\begin{array}{l}\text { 被占比 } \\
\text { 例(\%) }\end{array}$ & $\begin{array}{c}\text { 占被占总 } \\
\text { 面积比例 } \\
(\%)\end{array}$ \\
\hline 自然保护区 & 0.00 & 0.00 & 0.00 & 1.15 & 0.23 & 0.80 & 66.62 & 1.82 & 19.54 \\
\hline 森林公园 & 5.91 & 9.12 & 7.73 & 10.31 & 7.87 & 7.16 & 41.33 & 11.69 & 12.12 \\
\hline 风景名胜区 & 7.95 & 1.49 & 10.40 & 25.91 & 12.15 & 17.99 & 50.18 & 11.35 & 14.71 \\
\hline 地质遗迹 & 0.14 & 74.36 & 0.18 & 2.46 & 3.92 & 1.71 & 0.00 & 0.00 & 0.00 \\
\hline 饮用水源保护区 & 1.86 & 3.72 & 2.44 & 7.29 & 4.15 & 5.06 & 11.84 & 5.43 & 3.47 \\
\hline 行蓄洪区 & 0.00 & 0.00 & 0.00 & 1.54 & 2.09 & 1.07 & 20.96 & 2.67 & 6.14 \\
\hline 重要渔业水域 & 0.00 & 0.00 & 0.00 & 0.00 & 0.00 & 0.00 & 0.00 & 0.00 & 0.00 \\
\hline 重要湿地 & 33.20 & 15.17 & 43.44 & 64.34 & 5.90 & 44.68 & 46.50 & 3.07 & 13.64 \\
\hline 清水通道维护区 & 0.36 & 3.12 & 0.47 & 12.38 & 8.27 & 8.60 & 54.01 & 11.15 & 15.84 \\
\hline 生态公益林区 & 3.79 & 16.86 & 4.96 & 3.77 & 13.44 & 2.62 & 6.58 & 7.13 & 1.93 \\
\hline 水源涵养区 & 23.22 & 5.09 & 30.38 & 14.85 & 3.56 & 10.32 & 43.02 & 4.42 & 12.61 \\
\hline 合计 & 76.43 & 5.63 & 100.00 & 144.00 & 5.07 & 100.00 & 341.03 & 4.00 & 100.00 \\
\hline
\end{tabular}

生态保护空间的建设占用类型结构分析. 总体上, 三类耦合区域中农居空间占用比例最高, 分别为 $51.87 \% 、 36.50 \%$ 和 $41.94 \%$; 其它建设空间占用比例最低, 分别为 $1.50 \% 、 1.03 \%$ 和 $0.46 \%$; 其余各类建设空 间的占用比例差异较大，城镇空间占用比例方面，较不协调区域最高、基本协调区域次之、不协调区域 最低，分别为31.22\%、19.77\%和14.99\%; 农村居民点空间占用比例方面，不协调区域最高、基本协调区 域次之、较不协调区域最低, 分别为 $51.87 \% 、 41.94 \%$ 和 $36.50 \%$. 独立工矿空间占用比例方面, 不协调区 域最高, 较不协调区域次之, 基本协调区域最低, 分别为 $18.27 \% 、 10.03 \%$ 和 $6.09 \%$, 呈逐步降低趋势; 道 路交通空间占用比例则呈现相反趋势, 不协调区域比例最低, 较不协调区域次之, 基本协调区域最高, 分别为 $13.35 \% 、 21.23 \%$ 和 $31.74 \%$, 逐渐上升(表5).

表5 各耦合类型区生态保护空间建设占用类型结构统计

Tab.5 Statistics of Area and ratio of construction space which invades the ecological protection space in different regions

\begin{tabular}{|c|c|c|c|c|c|c|}
\hline \multirow[b]{2}{*}{$\begin{array}{c}\text { 建设空间 } \\
\text { 类型 }\end{array}$} & \multicolumn{2}{|c|}{ 不协调区域 } & \multicolumn{2}{|c|}{ 较不协调区域 } & \multicolumn{2}{|c|}{ 基本协调区域 } \\
\hline & $\begin{array}{c}\text { 占用生态保 } \\
\text { 护空间面积 } \\
\left(\mathrm{km}^{2}\right)\end{array}$ & $\begin{array}{l}\text { 占建设占用 } \\
\text { 总量比例(\%) }\end{array}$ & $\begin{array}{c}\text { 占用生态保 } \\
\text { 护空间面积 } \\
\left(\mathrm{km}^{2}\right)\end{array}$ & $\begin{array}{l}\text { 占建设占用 } \\
\text { 总量比例(\%) }\end{array}$ & $\begin{array}{c}\text { 占用生态保 } \\
\text { 护空间面积 } \\
\left(\mathrm{km}^{2}\right)\end{array}$ & $\begin{array}{l}\text { 占建设占用 } \\
\text { 总量比例(\%) }\end{array}$ \\
\hline 城镇空间 & 11.47 & 14.99 & 45.10 & 31.22 & 67.54 & 19.77 \\
\hline 农村居民点 & 39.68 & 51.87 & 52.72 & 36.50 & 143.26 & 41.94 \\
\hline 独立工矿空间 & 13.98 & 18.27 & 14.49 & 10.03 & 20.80 & 6.09 \\
\hline 道路交通空间 & 10.21 & 13.35 & 30.66 & 21.23 & 108.41 & 31.74 \\
\hline 其它建设空间 & 1.15 & 1.50 & 1.48 & 1.03 & 1.58 & 0.46 \\
\hline 合计 & 76.49 & 100.00 & 144.46 & 100.00 & 341.59 & 100.00 \\
\hline
\end{tabular}




\section{3 结论与讨论}

以江苏省为案例区，在划定生态功能保护区、提取建设空间分布信息的基础上，分析了生态保护空间 与建设空间的耦合特征，将案例区划分为不协调、较不协调和基本协调三种耦合区域，并分析了不同耦 合类型区域生态功能保护区的建设空间占用特点. 结果表明: (1)生态保护与建设空间耦合不协调区域包 括常州和无锡两市，面积 $9172.18 \mathrm{~km}^{2}$ ，约占全省 $8.70 \%$; 较不协调区域包括南京、苏州及宿迁三市，面积 $23623.84 \mathrm{~km}^{2}$ ，占全省 $22.40 \%$; 其它地市属于基本协调区域，面积 $72687.52 \mathrm{~km}^{2}$ ，占全省 $68.91 \%$. 在未来的 区域发展中应控制生态保护空间比重较高地区的建设空间增长速度, 减缓人口、经济活动规模扩张, 减 轻生态系统压力; 适度提高生态保护空间比重较低地区的建设空间增长速度, 促进人口、经济集聚, 以推 动区域总体经济增长. (2)不协调和较不协调区域中, 生态保护空间的建设占用比例较高, 且重要湿地、水 源涵养区及风景名胜区的建设占用规模相对较大; 基本协调区域中, 生态保护空间的建设占用比例较低, 但自然保护区、清水通道维护区、重要湿地、水源涵养区的建设占用规模较大; 未来应重点控制空间开 发对重要湿地、水源涵养区、风景名胜区、自然保护区、清水通道维护区等的占用, 并优先调整占用水 源涵养区和清水通道维护区的建设空间. (3)各耦合类型区中, 农村居民点占用生态功能保护区面积比例 最高, 未来可优先通过农居点的布局调整减少对生态功能保护区的占用, 增强生态服务功能. 不协调和 较不协调区域中, 独立工矿占用生态功能保护区的比例相对较高，未来应重点控制城镇、工矿开发对生 态保护空间的占用. 基本协调区域中, 道路交通空间占用生态功能保护区的比例较高, 未来的交通建设 应主动避让各类生态功能保护区.

控制生态功能保护区比例较高的地区建设空间增长, 适度提高生态功能保护区比例较低地区建设空 间比例，仅指出了建设空间比例调整的方向，适建空间比例的确定还需要综合考虑生态和农业的空间需 求. 生态功能保护区的边界可以作为中小尺度上各类建设空间布局与调整的依据, 但有序引导生态功能 保护区内的人口、产业逐步外迁, 削减人口、经济的规模, 是形成合理生态保护空间格局、缓解生态系 统的压力、增强生态系统的稳定性和生态服务功能的重要保障, 是进一步讨论的重点.

\section{4 参考文献}

[1] 傅伯杰, 刘国华, 陈利顶等. 中国生态区划方案. 生态学报, 2001, 21(1): 1-6.

[2] Benfield FK, Terris J, Vorsanger. Solving sprwal: Models of smart growth in communities across America. Natural Resources Defense Council, 2001: 137-138.

[3] Wu J, Plantinga AJ. The influence of public open space on urban spatial structure. Journal of Environmental Economics and Management, 2003, (46): 288-309.

[4] 刘海龙. 从无序蔓延到精明增长——美国“城市增长边界”概念述评. 城市问题, 2005, (3): 67-72.

[5] 王 波, 陈 雯, 赵海霞. 太湖地区环境敏感地空间分布及对策——苏州市为例. 湖泊科学, 2008, 20(3): 369-374.

[6] 邹长兴, 沈谓寿. 生态安全研究进展. 农村生态环境, 2003, 19(1): 56-59.

[7] 任志远, 黄 青, 李 晶. 陕西省生态安全及空间差异定量分析. 地理学报, 2005, 60(4): 597-606.

[8] 周 霞, 张林艳, 叶万辉. 生态空间理论及其在生物人侵研究中的应用. 地球科学进展, 2002, 17(4): 588-592.

[9] 燕守广, 沈渭寿, 江峰琴. 江苏省重要生态功能保护区的分类及建立方法. 生态与农村环境学报, 2007, 23(1): 16-18, 47.

[10] 刘耀涁, 宋学峰. 城市化与生态环境耦合模式及判别. 地理科学, 2005, 25(4): 408-414.

[11] 陈 雯, 段学军, 陈江龙等. 空间开发功能区划的方法. 地理学报, 2004, 59(增刊): 53-58. 